\title{
Paediatric or pediatric dentistry?
}

\author{
K. J. Toumba
}

Published online: 9 April 2013

(C) European Academy of Paediatric Dentistry 2013

Paediatrics (or pediatrics) is the branch of medicine that deals with the medical care of children. A medical practitioner who specialises in this branch of medicine is known as a paediatrician (or pediatrician), and similarly in dentistry a dental practitioner who specialises in the dental treatment of children is known as a paediatric (or pediatric) dentist or alternatively as a paedodontist (or pedodontist). However, there is much confusion as to which of the two spellings is correct and many are unaware of the etymology (origin) of the word. Many students, general practitioners and indeed specialists have frequently asked "is it paediatric or pediatric dentistry that is the correct spelling?" Further confusion is caused by some podiatry words beginning with "pedo" (relating to feet).

In ancient times physicians like Hippocrates understood the differences in growing and developing children and that this necessitated different treatment and management. Byzantine physicians made significant contributions to child care and built baby shelters (children's hospitals). Later, a Persian physician (Al-Razi, 865-925 CE) published a short treatise on diseases among children and the first printed book on paediatrics (or pediatrics) was in Italian (Bagellardo 1472). Paediatrics (or pediatrics) as a specialised field of medicine developed in the mid-19th century, with the German Abraham Jacobi (1830-1919), who later worked in New York, USA, regarded as the father of paediatrics (or pediatrics).

The first paediatric (or pediatric) hospital was the Hôpital des Enfants Malades (Hospital for Sick Children), which opened in Paris in 1802 and accepted patients up to

K. J. Toumba $(\bowtie)$

Department of Paediatric Dentistry, Leeds Dental Institute,

Clarendon Way, Leeds LS2 9LU, UK

e-mail: k.j.toumba@leeds.ac.uk the age of 15 years. Following this a separate Paediatric (or Pediatric) Pavillion was created at the Charité Hospital in Berlin in 1830 and later in St. Petersburg (1834), Vienna (1837) and Wroclaw (1837). Great Ormond Street Hospital for Sick Children in London was formed in 1852 and in the USA the first children's hospitals were the Children's Hospital of Philadelphia (1855) and then Boston Children's Hospital (1869).

Academically the first University Chair of Paediatrics (or Pediatrics) in the UK was founded in Scotland in 1924 with the appointment of Professor Leonard Findlay. The first Chair of Paediatrics (or Pediatrics) in the USA was established earlier, in 1888, with the appointment of Professor Thomas Morgan Rotch at Harvard. In dentistry the first European Professor of Paediatric (or Pediatric) Dentistry was Gottorm Toverud at the University of Oslo, Norway. Scholarly journals for paediatrics (or pediatrics) were founded from 1884 (Archives of Pediatrics) and the first for paediatric (or pediatric) dentistry was in 1933 (Journal of Dentistry for Children). The American Academy of Pediatric Dentistry was founded in 1947, with its journal Pediatric Dentistry first published in 1978. By comparison, the European Academy of Paediatric Dentistry was founded in 1990 and our own journal was first published in 2000, originally as the European Journal of Paediatric Dentistry and since 2006 as the European Archives of Paediatric Dentistry.

The question still remains: "is paediatric or pediatric the correct spelling?" The word paediatric (or pediatric) originates from two Greek words: $\pi \alpha \tilde{\varsigma} \varsigma$ (pais or paedion $=$ child)

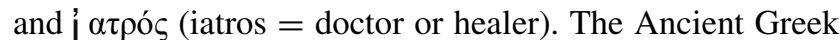
diphthongs $\langle\alpha \mathrm{l}\rangle$ and $\langle\mathrm{ol}\rangle$ were transliterated into Latin as $<$ ae $>$ and $<$ oe $>$. Therefore, the original spelling in English was "paediatric". Noah Webster (1758-1843), an American lexicographer and English spelling reformer, 
changed the spelling of many English words to simplify learning. His dictionary was first published in 1828 and exists today as the Merriam-Webster dictionary. Following Webster, words that were written with ae/æ or oe/œ in British English were spelt with just an e in American English.
Therefore "paediatric" (British and Commonwealth usage) was changed to "pediatric" (American usage). Therefore, both spellings are correct depending on which country you reside in or which style of English was used by your teachers. 